\title{
SIMPLICITY OF APPROACH TO TREATMENT OF THE INJURED HAND
}

\author{
P. S. London, Birmingham, England \\ From the Birmingham Accident Hospital
}

With the increasing interest taken in the surgery of the hand there have been striking advances in technique, materials and the standard of results obtained. The literature abounds with accounts of ingenious, elaborate and successful methods of treatment, especially treatment designed to reconstruct the naturally deformed or the mutilated hand. Clearly such successes have not been achieved without disappointments, and even disasters, but these have gone for the most part unremarked. There is in consequence considerable incentive to think of the mutilated hand as being in need of reconstruction and of saving injured parts with a view to later structural restoration by means of grafts and transplants of various kinds. The successes are published, the failures are regretted in private; the incentive is undiminished.

Against this background of technical virtuosity it may seem presumptuous to advocate a simple approach to treating injured hands but it offers ample opportunity for the surgeon who is interested rather than specially skilled in the subject to achieve satisfactory results in terms of function. The essence of manual skill is to feel and to grasp. For this purpose the

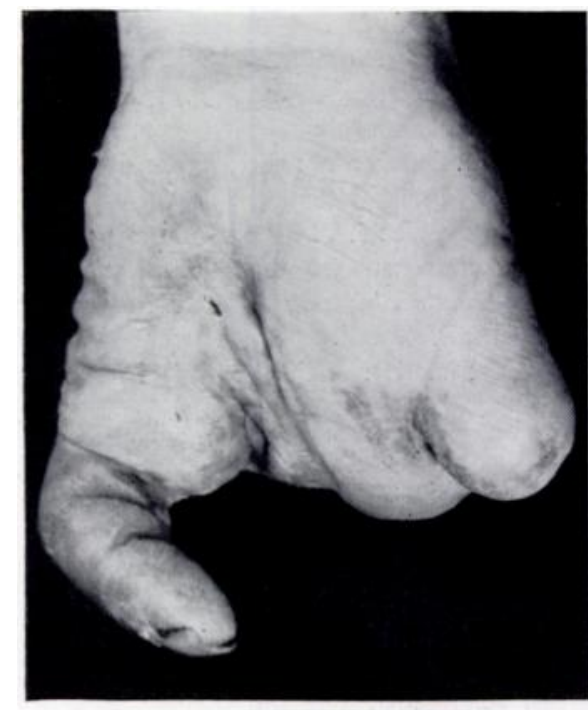

FiG. 1

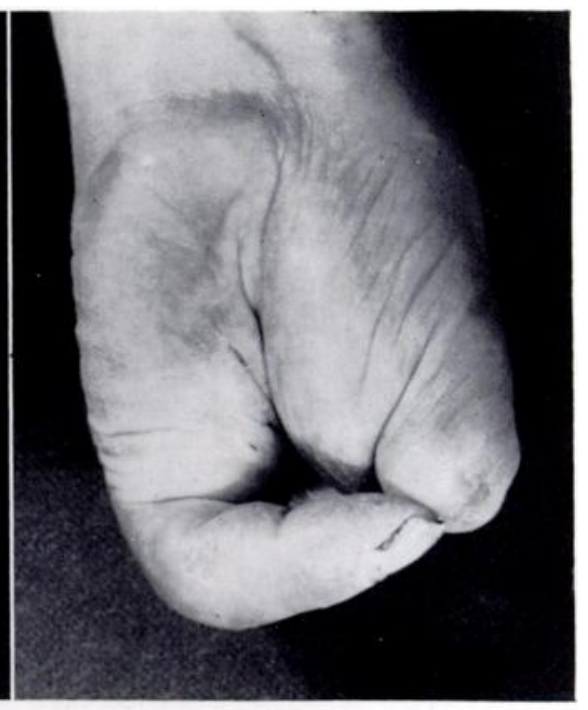

Fig. 2

The patient, a man of sixty-seven, made good use of this extremity. A fracture of the little finger was used to rotate it towards the stump of the thumb.

minimum requirement is skin with normal or nearly normal sensibility and at least two digits that can be brought firmly together and separated. Such a remnant is ungainly but it is useful and could not be made more useful by any addition to its structure (Figs. 1 and 2).

Moberg (1958) has stressed the importance of tactile gnosis-the ability to distinguish size, texture, consistency, shape and temperature by touch alone. Tactile gnosis is not to be expected in any graft that has been separated from its normal nerve supply. Many grafts will in time regain enough sensibility to protect against harmful influences. Testing with pin, wool or von Frey's hairs may suggest that reinnervation has proceeded to a gratifying extent but sensibility may still be well below the standard of tactile gnosis. When sensibility is 


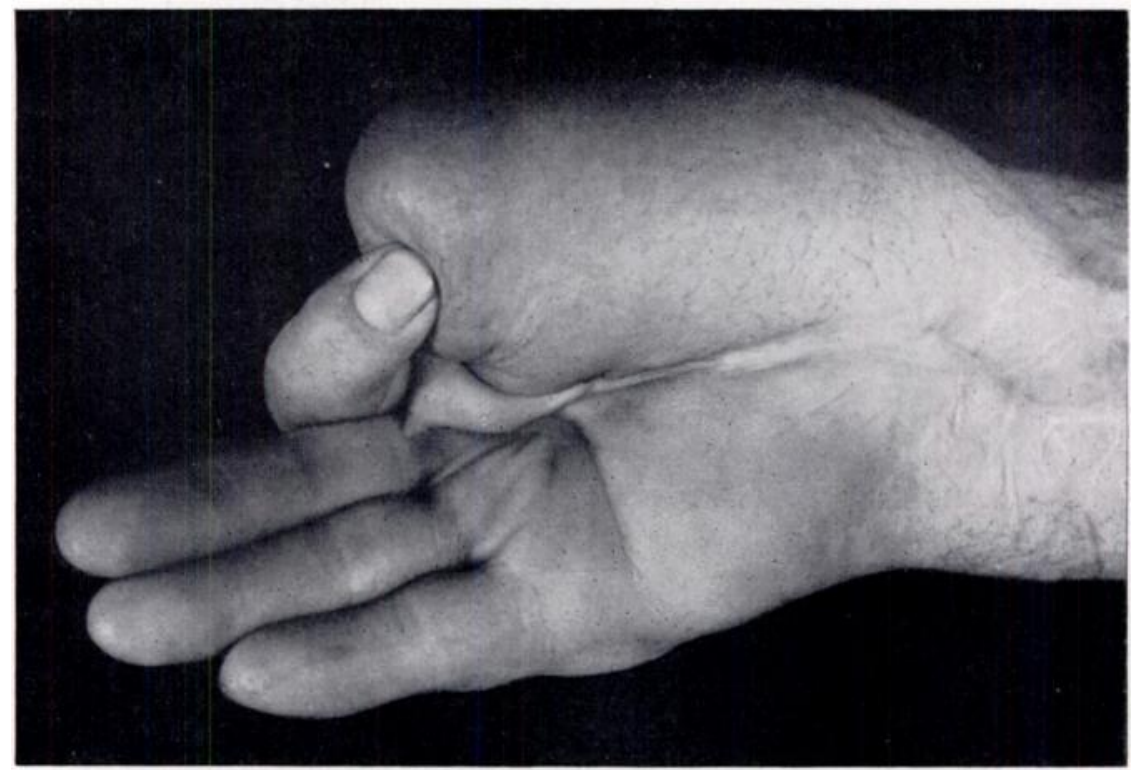

Fig. 3

This flap had been in place for twelve years but was uncomfortable, awkward and almost insensitive. The hand was well used, however, because the fingers were healthy.

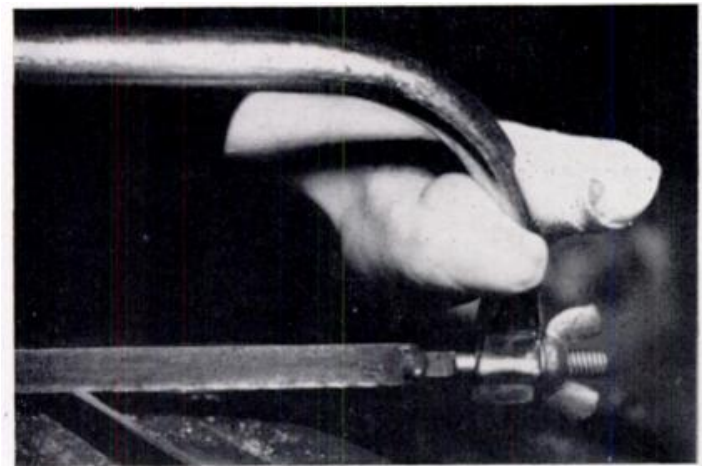

Fig. 4

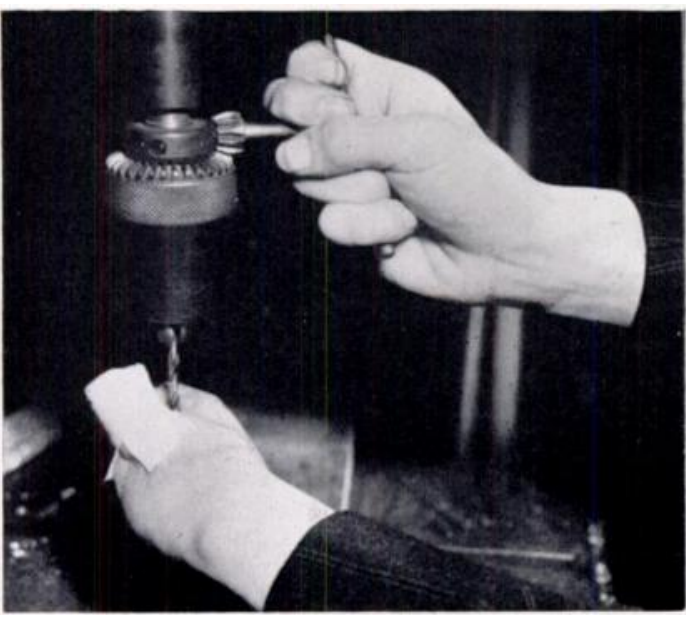

FIG. 5

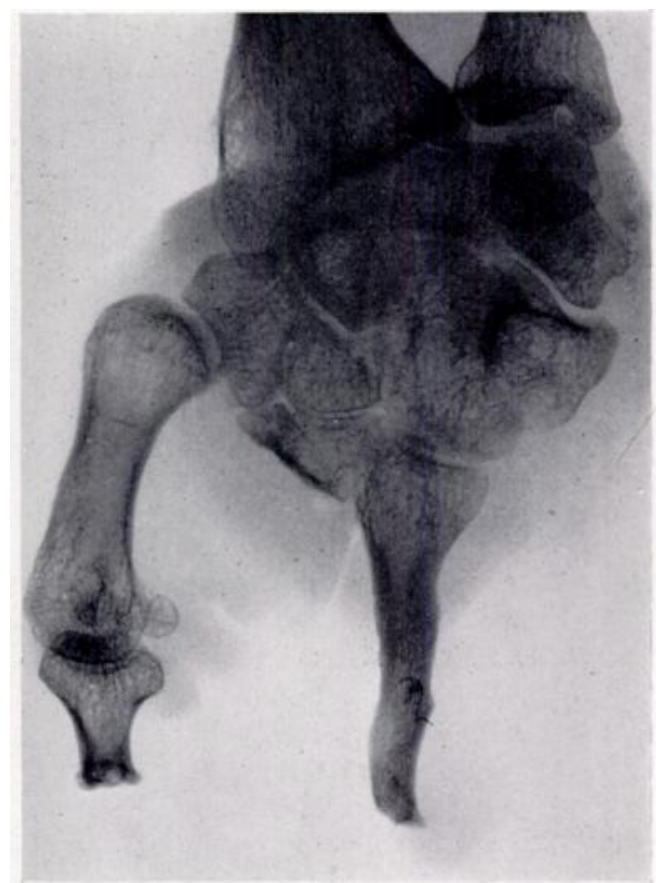

FIG. 6

Figs. 4 To 6

An opposition post formed from bone grafts and skin. Although in use the opposition post bears a dressing. This one healed and remained so-not all do. The radiograph shown in Figure 6 was taken in April 1960, many years after the repair. (By courtesy of Mr Mervyn Evans.) Figure 4 is reproduced by kind permission of the Editor, British Journal of Plastic Surgery.

vol. 43 B, No. 3, AUgust 1961

C 
tested by the patient's ability to manipulate small objects with the eyes closed the aptness of Moberg's concept of a blind or a sighted digit is strikingly demonstrated.

This at once calls in question the desirability of replacing skin on the most usefully perceptive parts of the hand by flaps and tubes bereft of their normal innervation and consequently blind or purblind. One or two fingers stripped of skin are often better amputated, but a thumb covered by abdominal skin may be a small handicap provided other digits possess

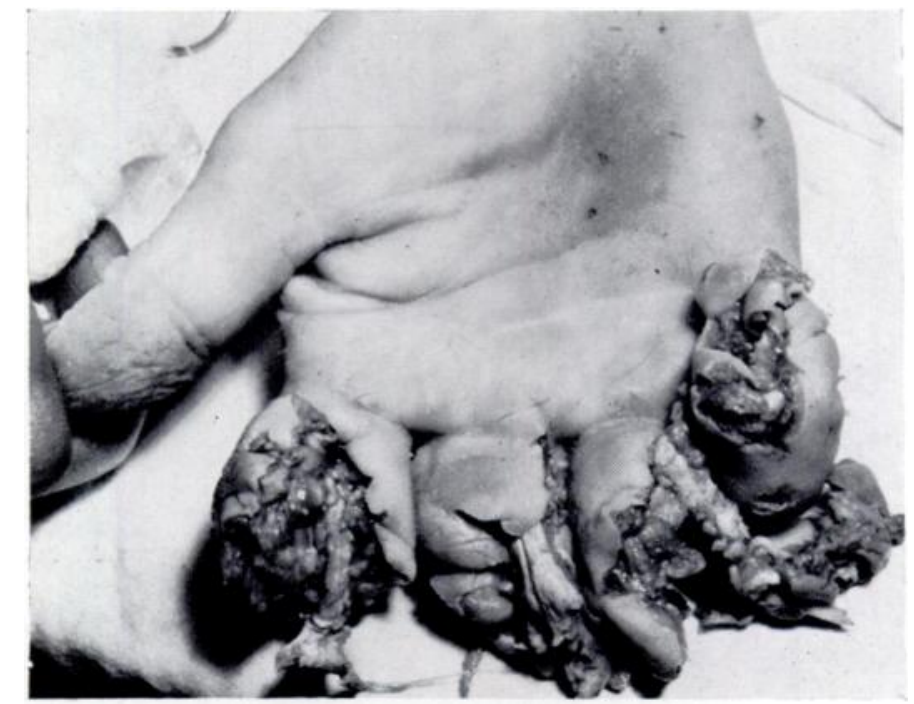

FIG. 7

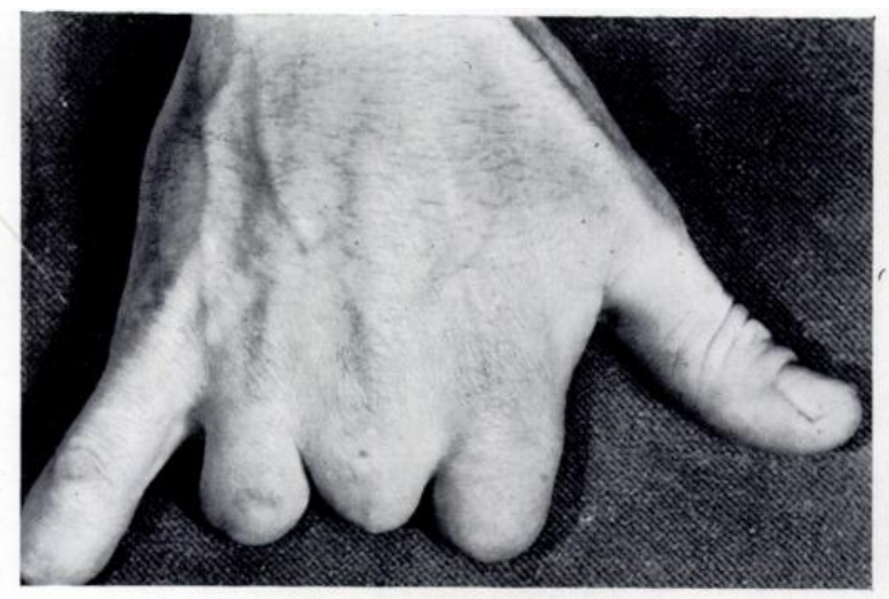

FIG. 8

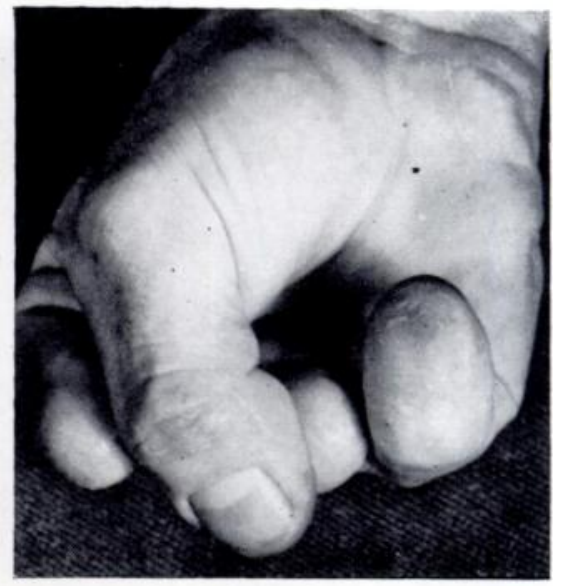

FIG. 9

Figs. 7 To 9

With careful trimming and closure useful stumps were preserved and retained tactile gnosis. (Reproduced from Modern Trends in Accident Surgery and Medicine, by permission of Messrs Butterworth \& Co. (Publishers) Ltd.)

enough tactile gnosis to compensate for the insensitiveness of the thumb (Fig. 3). An insensitive reconstruction that is also rigid is usually less successful in practice. Though it may be of creditable appearance, its inherent defects make it vulnerable and much more liable to ulceration than capable of healing. With nothing more than part of the thumb and a mere stump of carpus it may be worth fashioning an opposition post from grafts of skin and bone (Figs. 4 to 6), but it may turn out to be of small value. A thumb and a palm is not usually 
worth adding to surgically but even short sensitive stumps of fingers should be preserved (Figs. 7 to 9).

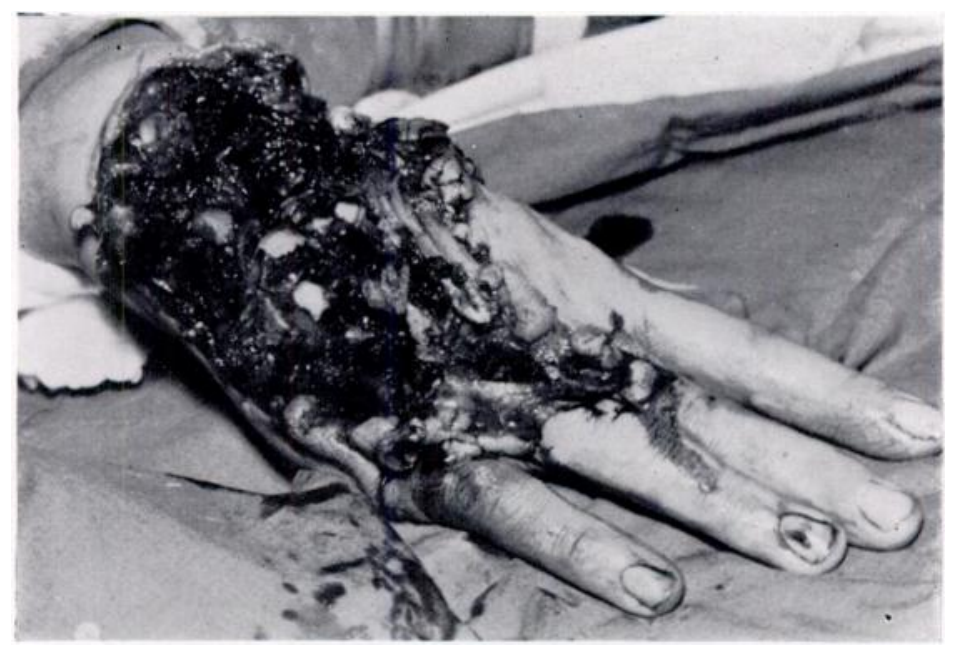

FIG. 10

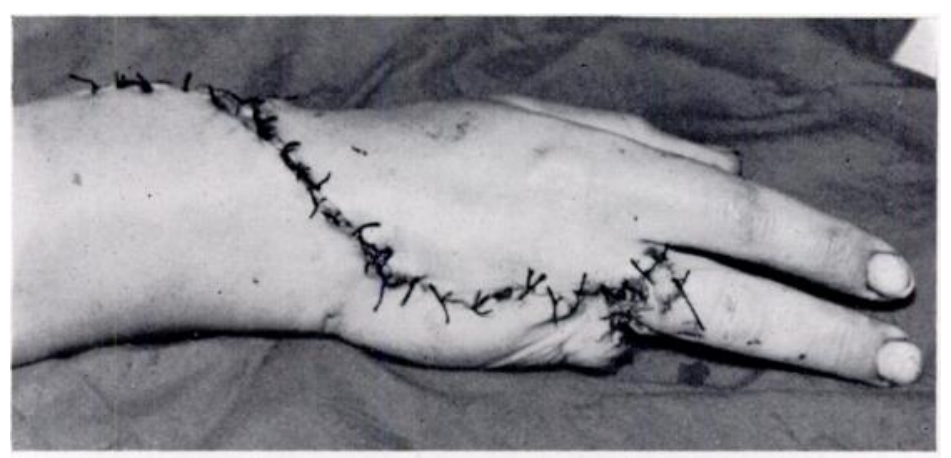

Fig. 11

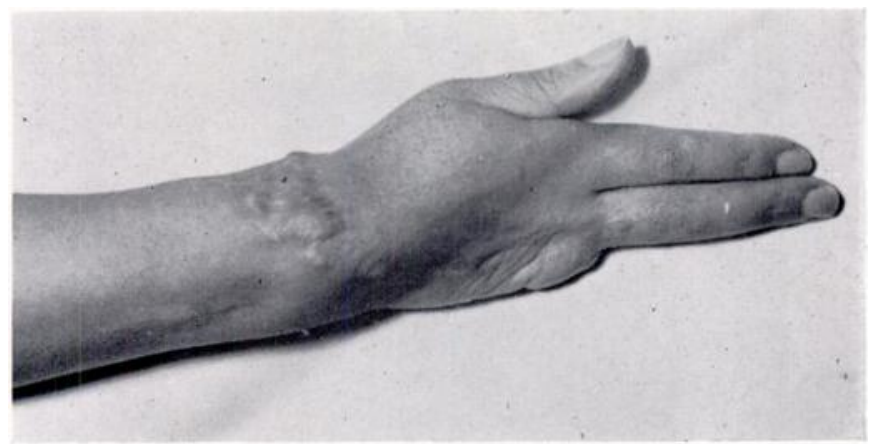

Fig. 12

Figs. 10 To 12

The little and ring fingers were not worth saving. The hand healed after one operation and the remaining digits regained almost full strength and range of movement.

In many instances the patient will be best served by simple surgical toilet and careful repair of the remaining structures that can reasonably be expected to be useful (Figs. 10 to 16).

vol. 43 B, No. 3, AUGUST 1961 
When the viability of important structures is in doubt they are often better retained in the first instance even though they may later have to be discarded (Figs. 17 to 19).

In other cases it is possible to maintain or restore tactile gnosis by using innervated skin from other parts of the hand and particularly from fingers that have been badly damaged.

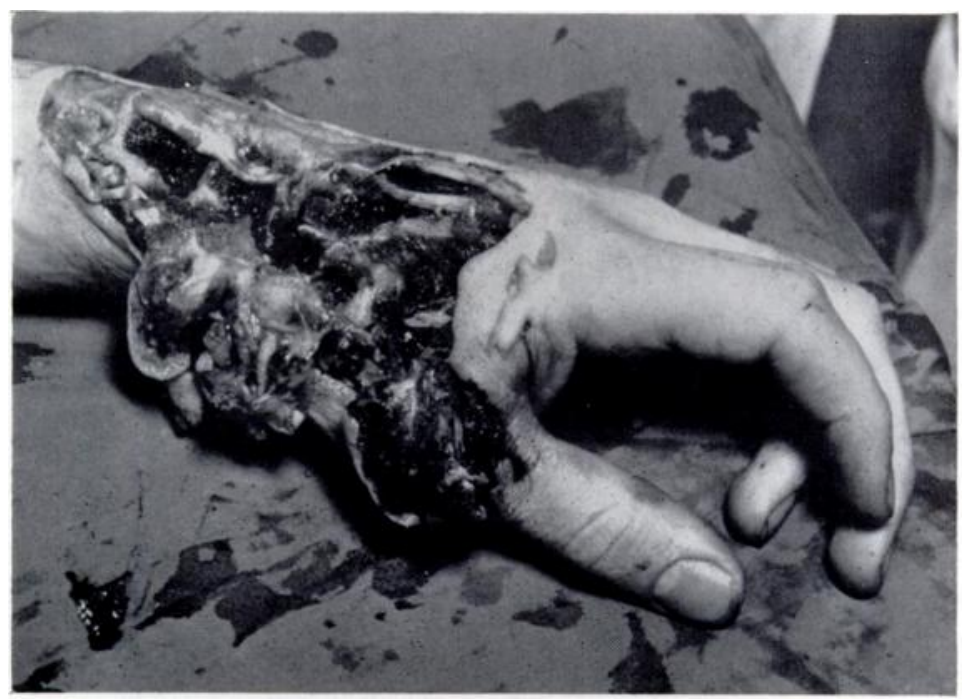

FIG. 13

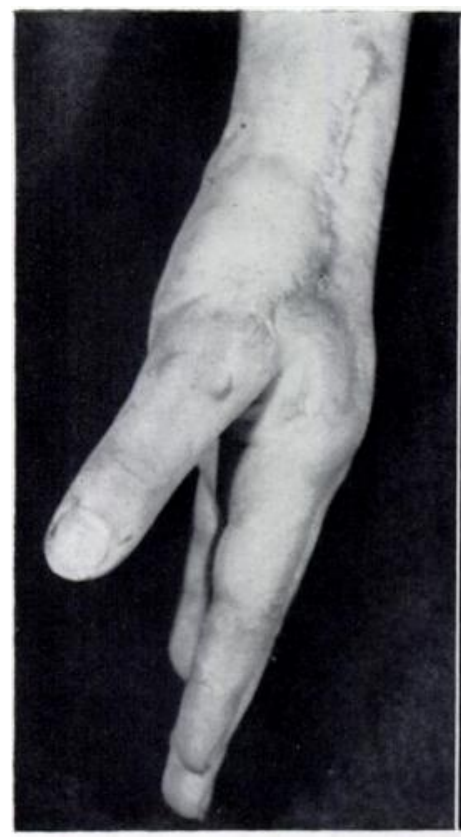

FIG. 14

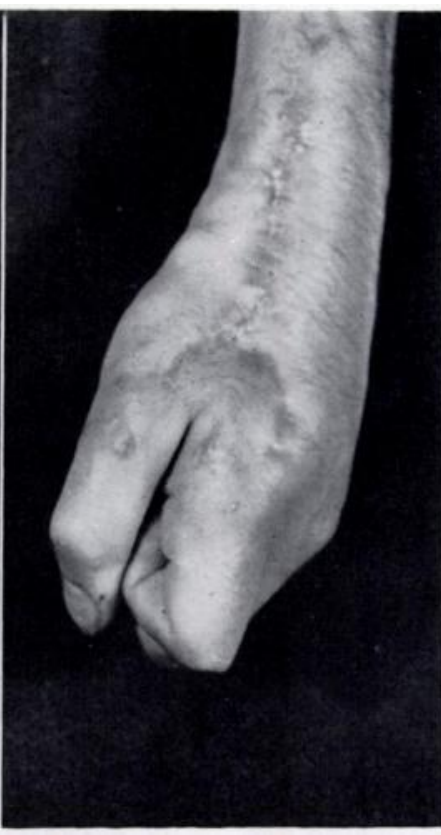

FIG. 15

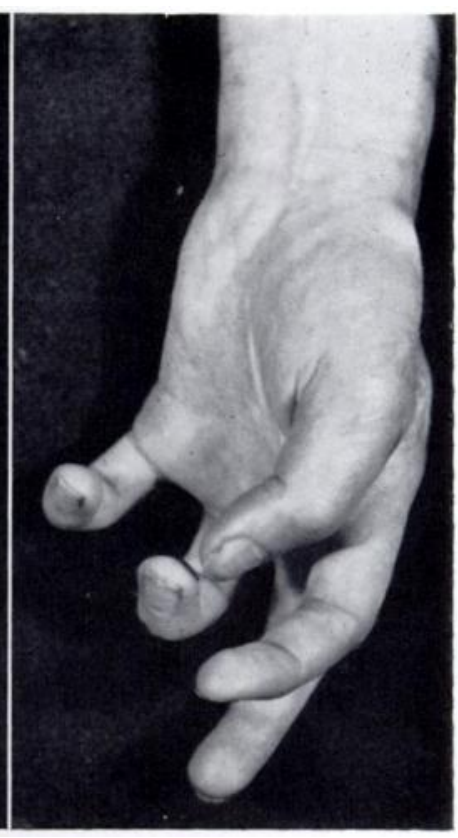

FIG. 16

Damage to tendons, skin and bone. No skin lost. Repair by suture of injured structures. Final function good in general though diminished in detail.

Though they may be amenable to reconstruction the process will be lengthy and may leave the patient with a finger that is useless and a handicap because of stiffness and insensibility (Figs. 11 and 12 and 20 to 29). The fact that a flap with a neurovascular pedicle may later 
have that pedicle cut through does not lessen the simplicity of the method and it may not significantly impair tactile gnosis (Figs. 30 to 32). From the patient's point of view it is advantageous to be spared the experience of having the hand sewn temporarily to some other part of the body.

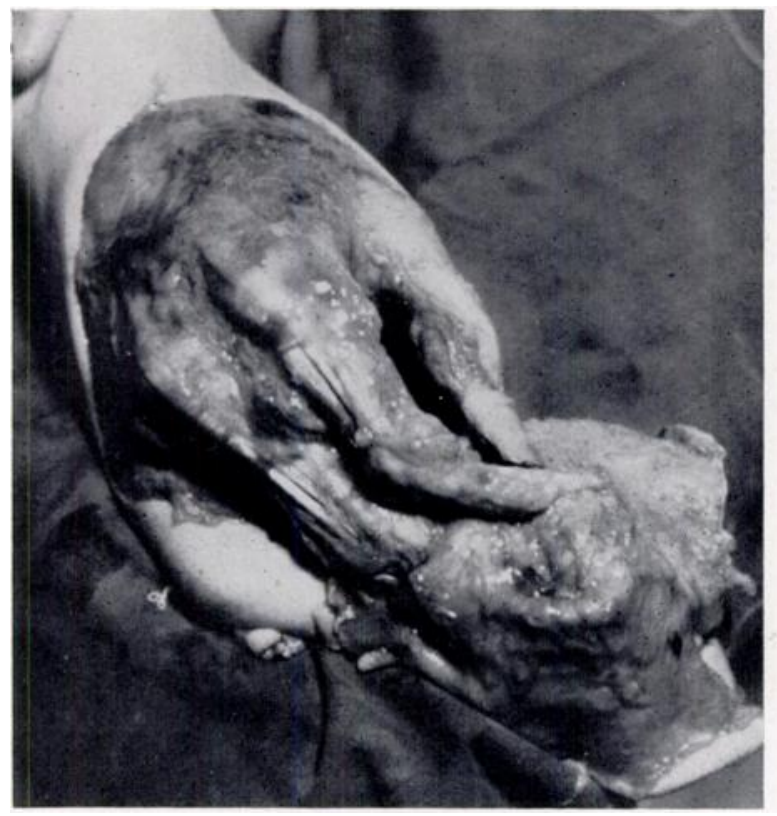

FIG. 17

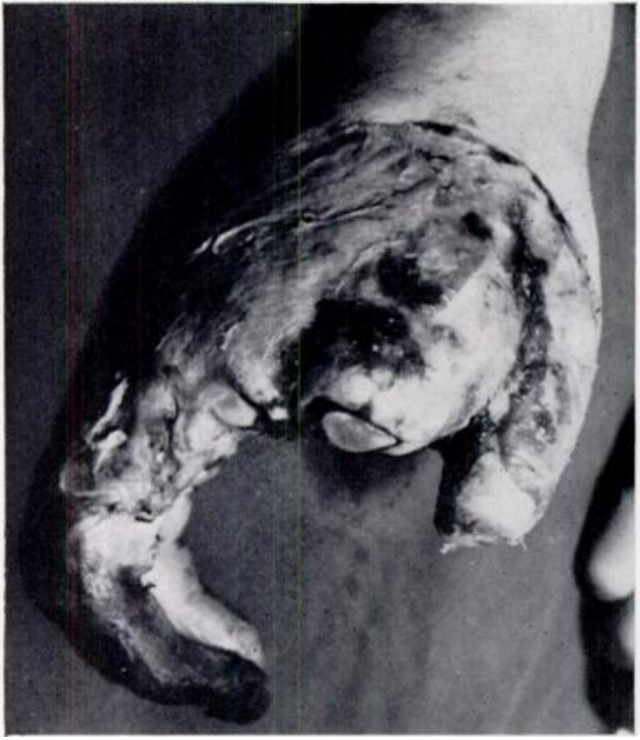

FIG. 18

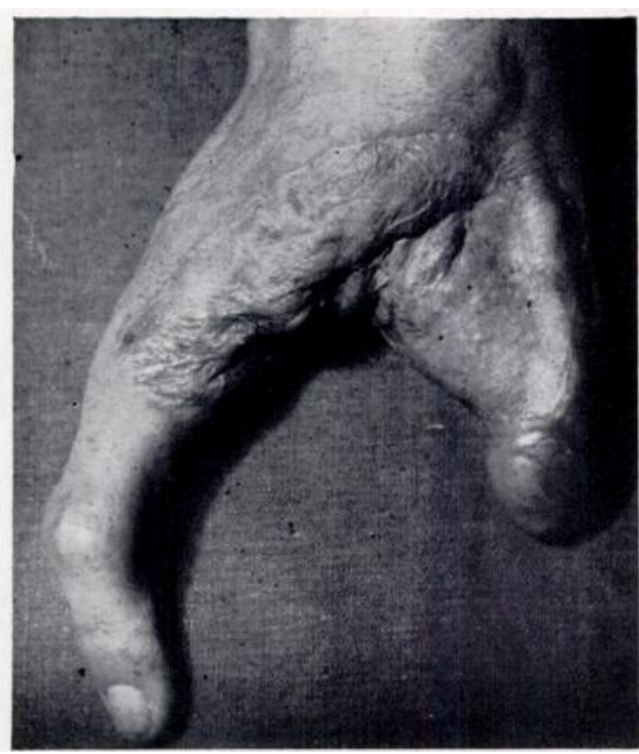

FIG. 19

Immediate amputation of index and long fingers and part of thumb. Ring finger subsequently died and after part of the metacarpus was removed a useful claw remained.

When tactile gnosis remains on reparable digits it is justifiable to go to considerable lengths to retain them. An initial simple procedure may not suffice and a more elaborate programme then becomes necessary (Figs. 33 to 36 ).

VOL. 43 B, No. 3, AUGUST 1961 

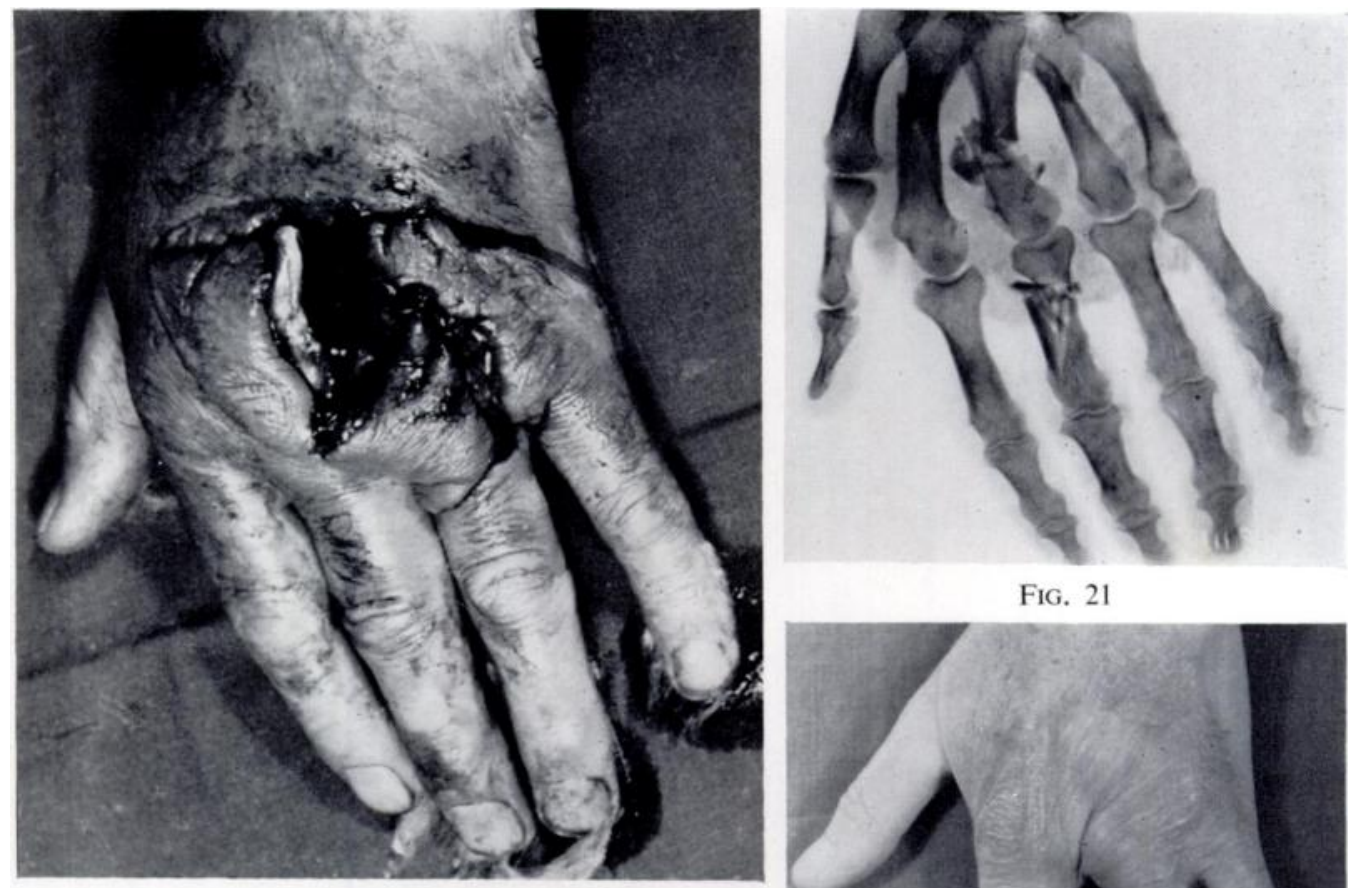

Fig. 21

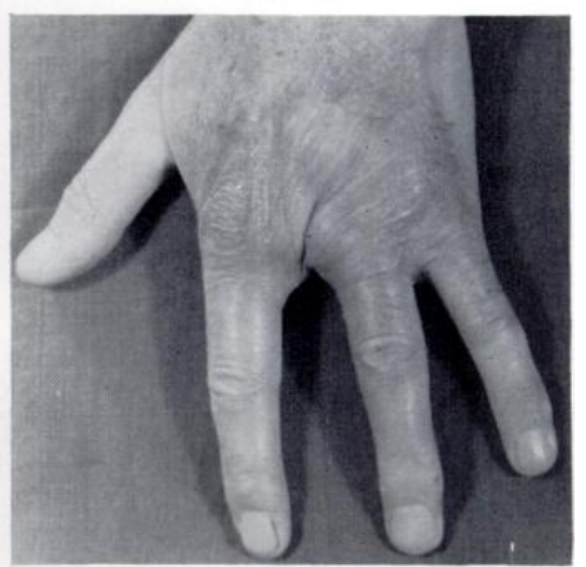

FIG. 23

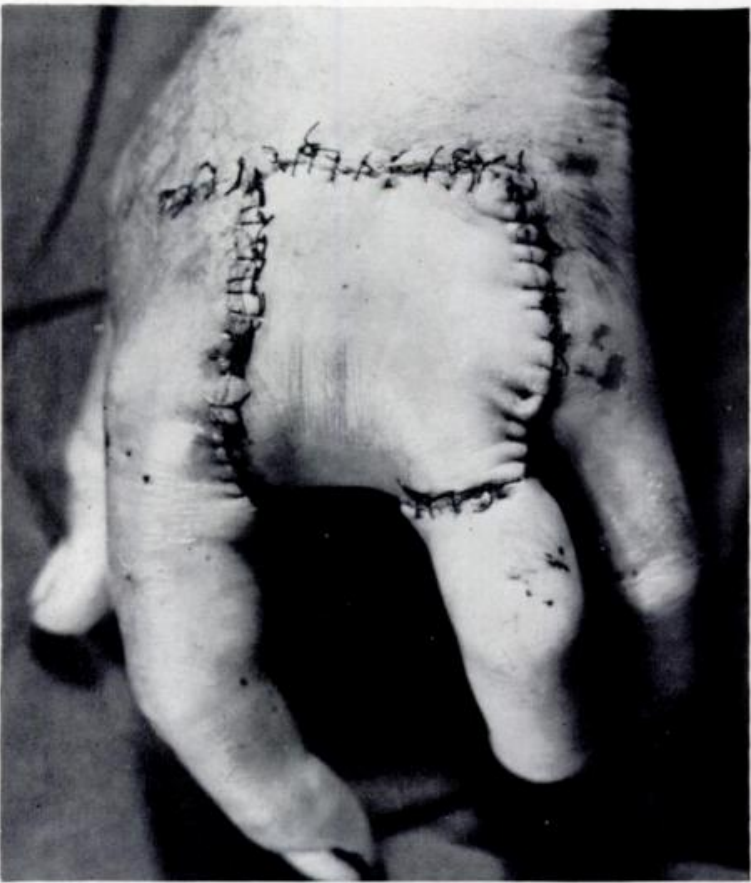

Fig. 22

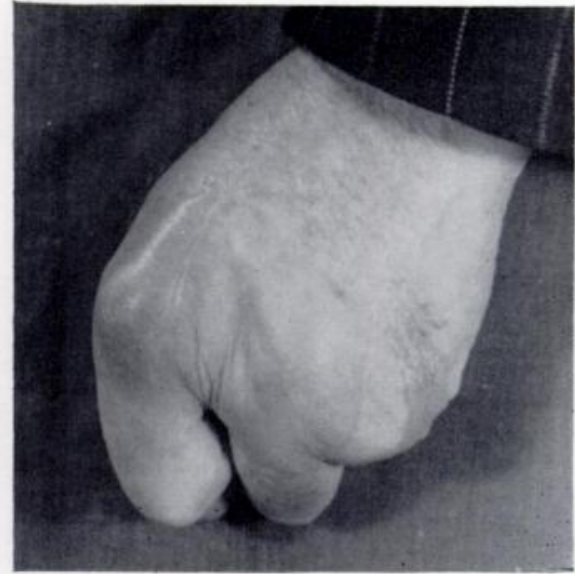

Fig. 24

Penetrating wound of the hand. Skin of long finger, which was technically reparable, used instead to fill defect with little impairment of eventual function. (Figures 20 to 22 are reproduced by kind permission of the Editor. British Journal of Plastic Surgery.) 


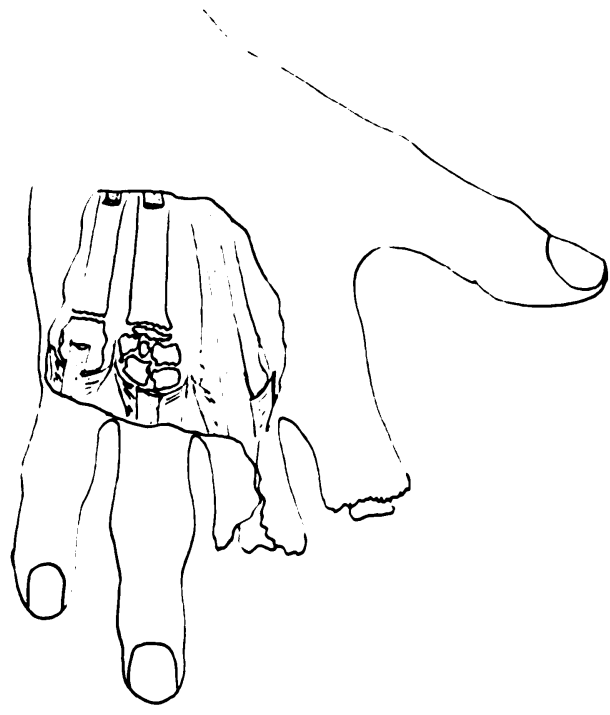

FiG. 25

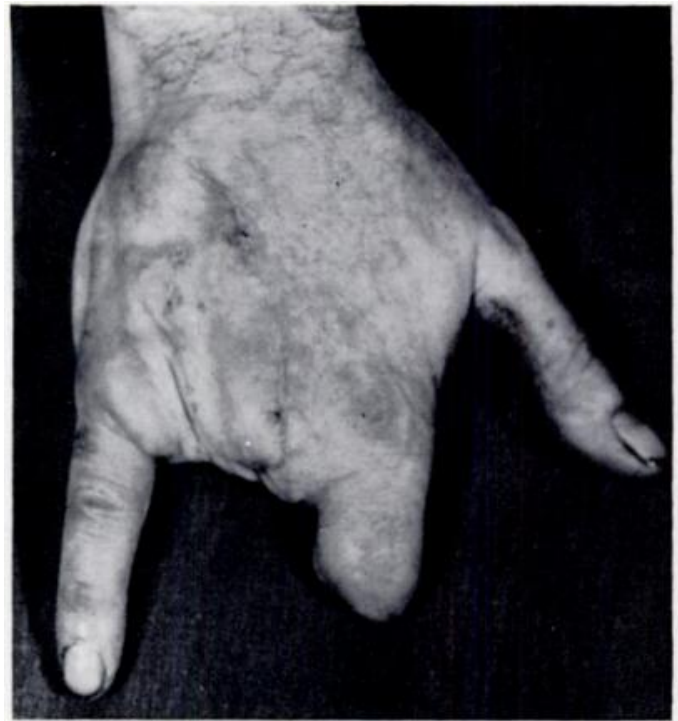

FIG. 26

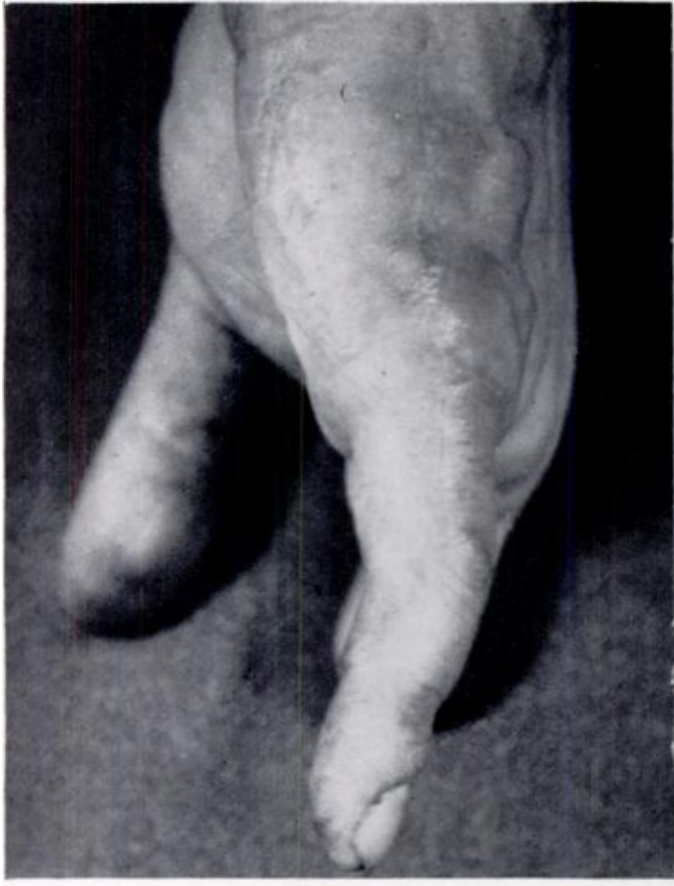

Fig. 27

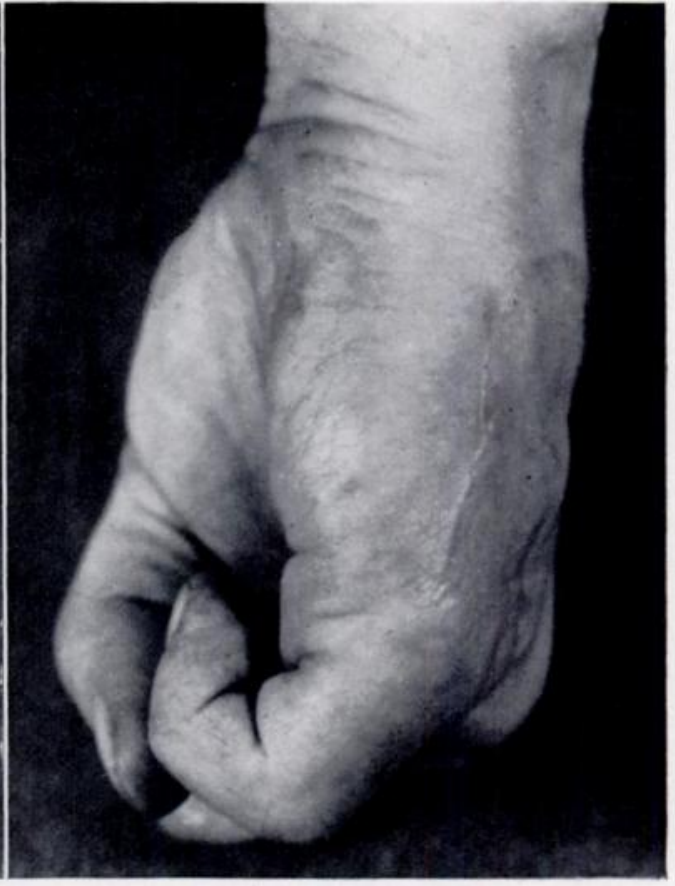

FiG. 28

Ring finger sacrificed to allow large defect to be made good by skin from the hand. Given the prospect of healing by first intention, the extensor tendon to the long finger was transplanted to the little finger and the fracture of the fifth metacarpal was fixed. Using the hand gainfully within one month of injury. (Reproduced from Modern Trends in Accident Surgery and Medicine, by permission of Messrs Butterworth \& Co. (Publishers) Ltd.) 


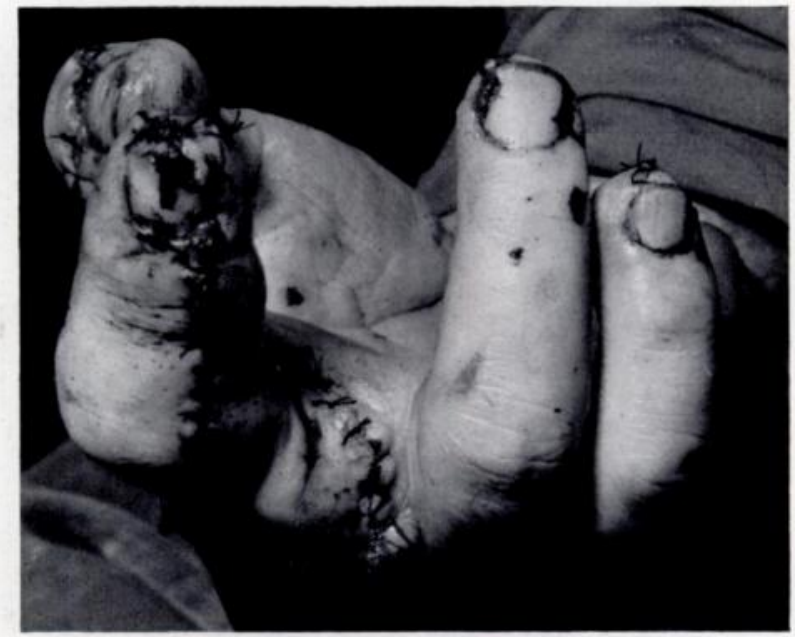

Fig. 29

A strip of skin with normal neurovascular supply was taken from the badly damaged middle finger to complete the index finger, which had lost skin from one side.

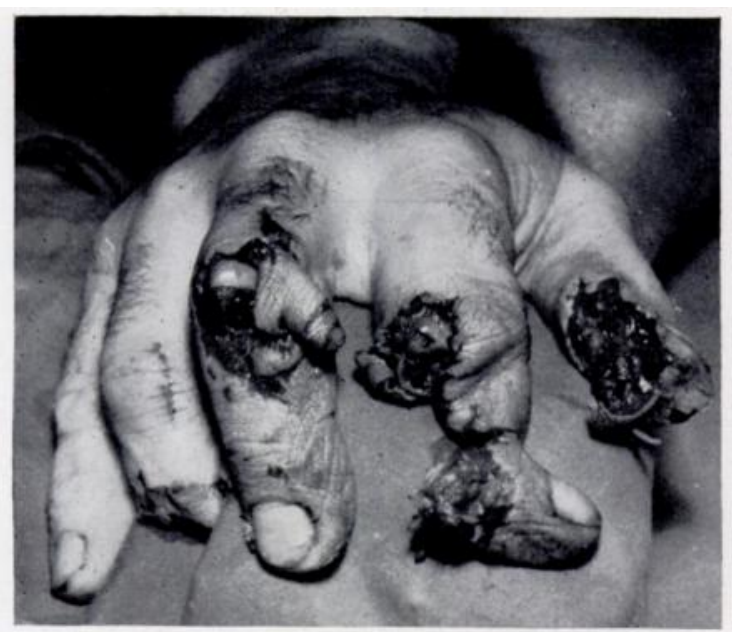

FIG. 30

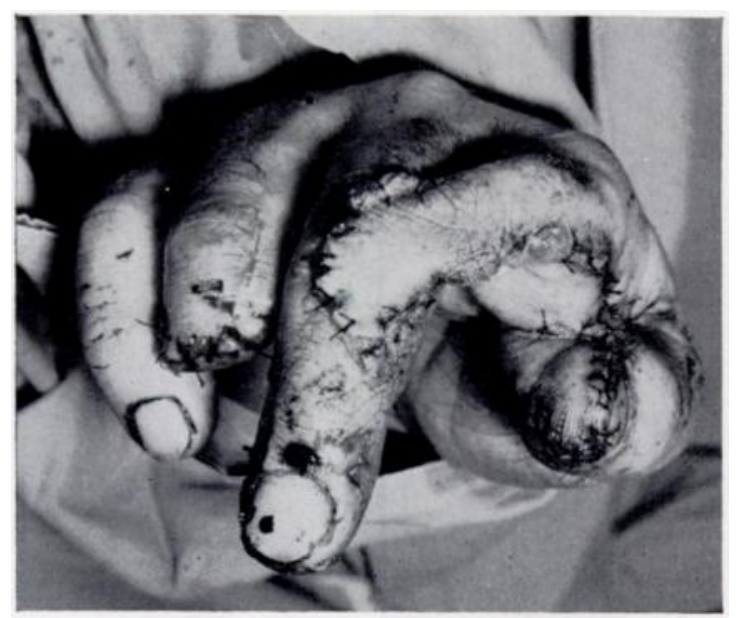

FIG. 32

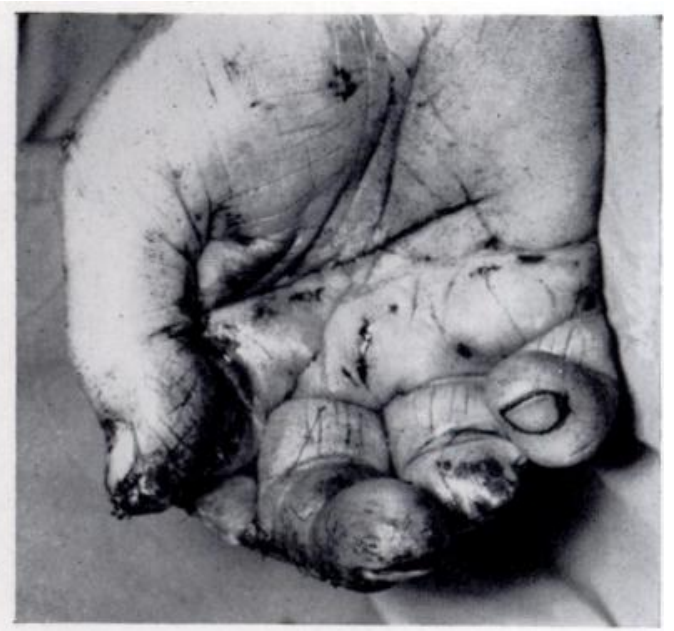

FIG. 31

Figs. 30 To 32

Stump of index finger split into three flaps which were used to complete the thumb and long finger. The third flap was used to clothe the raw surfaces leaving only a small area to be covered by split skin. 


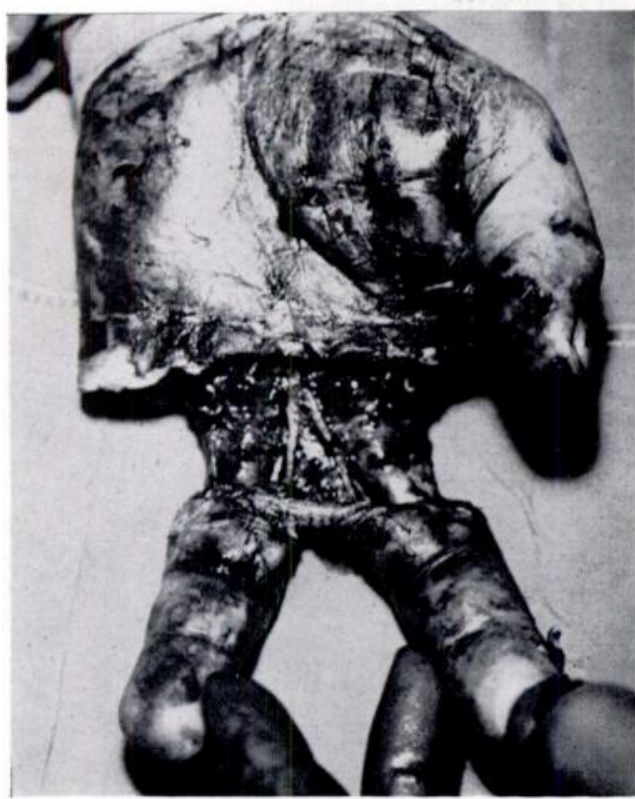

FiG. 33

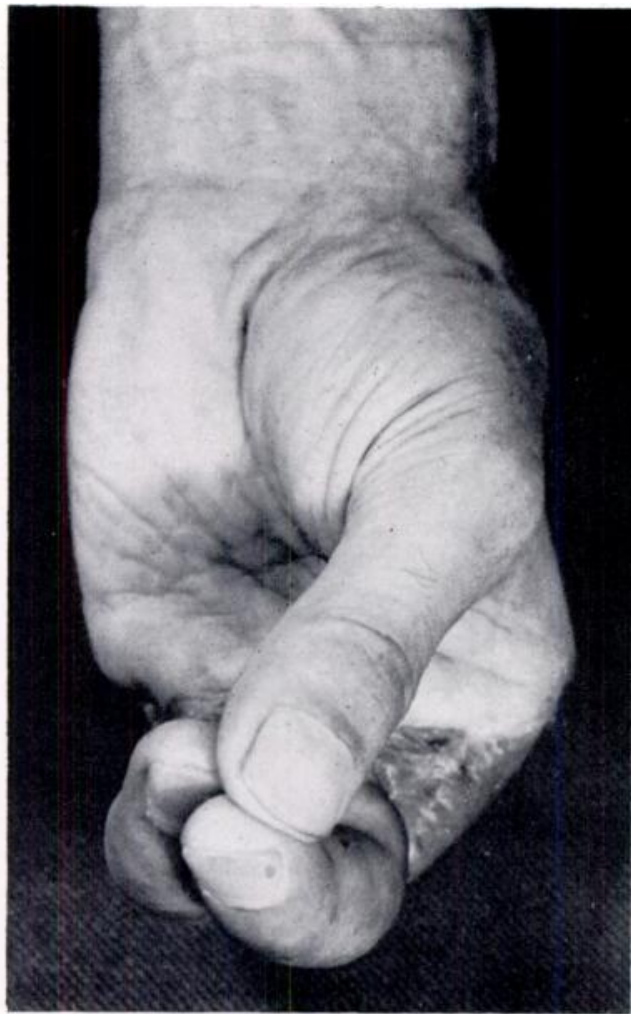

Fig. 35

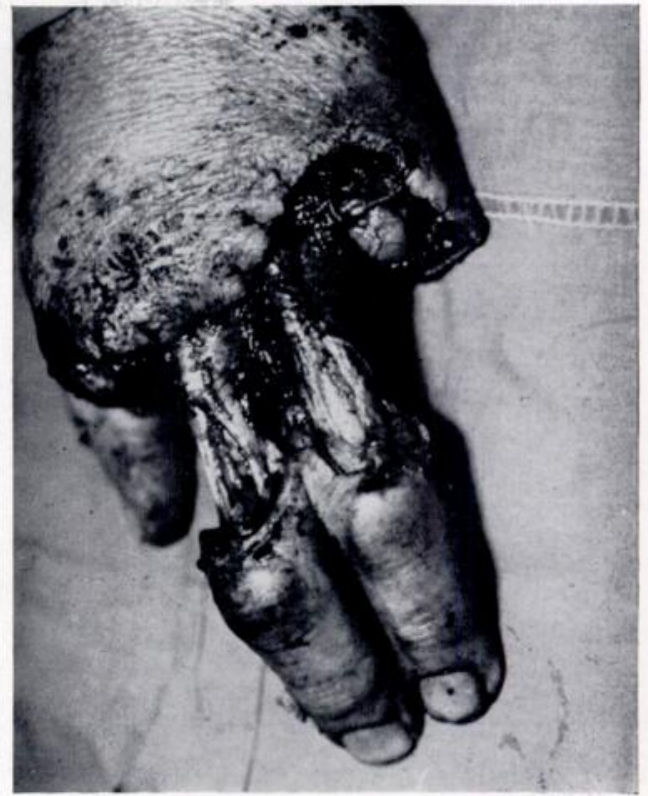

FiG. 34

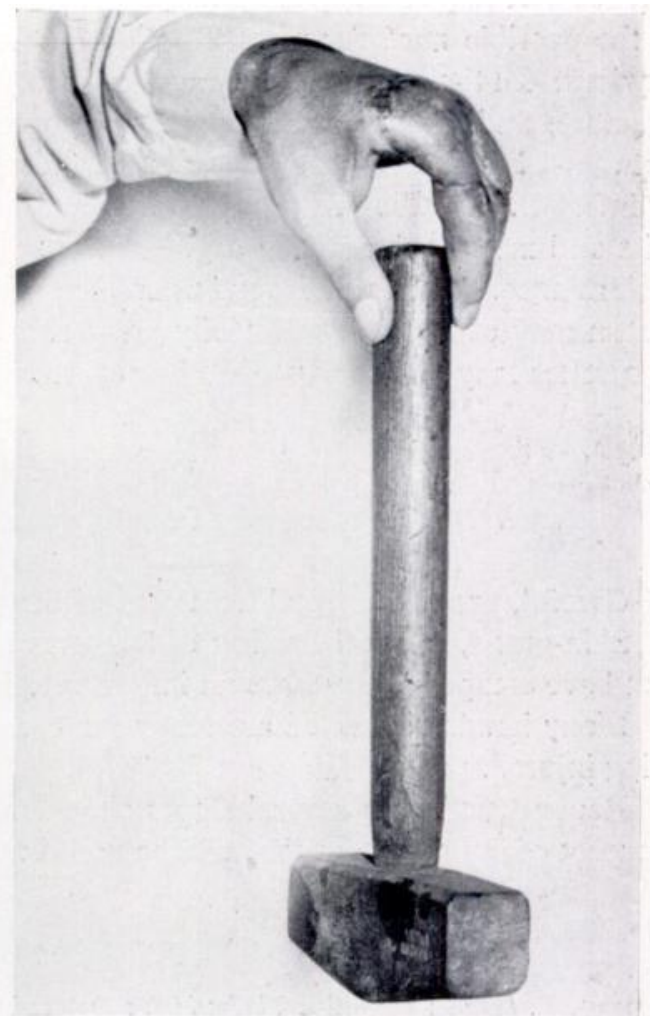

Fig. 36

The hand was crushed between rollers and the skin stripped from part of the palm and the bases of the fingers. It was stitched back under local anaesthesia but most of it died. The remaining living tissue included skin on the tips of the fingers, each with a neurovascular pedicle. Free skin grafting failed only on the bare bone of the phalanges. An abdominal flap was applied. The fingers were then too stiff and bent to be useful but were straightened by corrective arthrodesis. The hammer shown weighed 4 pounds. 


\section{DISCUSSION}

The approach advocated here is based upon the universal principle of treating wounds: to bring healthy, living tissues together and to keep them there until healed. This necessarily entails the sacrifice of dead and damaged tissue and the provision (by grafting) of a second healthy surface when one surface of the wound has been destroyed. The rest that assists healing may be best ensured by internal fixation of fractures.

In favourable cases, once the wound has healed successfully the remnant of the hand is ready for use; in others more surgery is required, but it is not unusual to find that secondary operations could have been included advantageously in the first. This saves much time. avoids many of the physical troubles of prolonged disuse, and may make physiotherapy entirely unnecessary. Apart from this there are considerable psychological advantages. The patient does not have time to develop a fixed mental image of a disabled extremity. Any initial enthusiasm to get back to work is liable to be sapped by prolonged idleness and may suffer further from the persuasions of others that too early a return to work may weaken a claim for compensation. Much can be done to mitigate these troubles by the earliest possible meeting of the patient and the surgeon who is going to look after his hand. It may not at first be possible to make an accurate or detailed forecast of the treatment required and the result to be expected, but the patient can at least be given reason to have confidence in his surgeon; this should be reinforced by further discussion as the outcome becomes confidently discernible.

The initial operation is crucial; it must be designed with the patient's needs and the prospects of useful survival of the injured structures clearly in mind. It must take account of the possible need for reconstruction and must lay the foundations for whatever may be required. On the other hand, it must not in any way jeopardise the survival of useful remaining structures and it must be followed by prompt healing. The urge to conserve may have to be restrained lest it burden nimble parts with others that are stiff and numb, or hazard them by infection spreading from a part that had been better discarded. That brilliant operations exist and may be feasible in a given case is not in itself the slightest justification for their performance. Much will depend upon the patient's needs and upon his ability. The intelligent person may overcome successfully grave shortcomings of feeling and movement; the simple or careless may not be trusted to keep even a small flap intact, let alone use it.

\section{SUMMARY}

1. The success of any method of treating the injured hand is to be measured by the use that is made of the remnant.

2. Careful, prompt surgical treatment of the wound will usually allow prompt healing.

3. Skin-grafts, internal fixation of fractures and the eking out and rearrangement of tissues that have escaped injury have an important place in primary treatment.

4. Many hands so treated are ready for use after one operation and within a few weeks of being injured.

5. Reconstruction in several stages should not be carried out unless it offers a reasonable prospect of improvement that will be useful to the particular patient.

\section{REFERENCE}

Moberg, E. (1958): Objective Methods for Determining the Functional Value of Sensibility in the Hand. Journal of Bone and Joint Surgery, 40-B, 454. 